\title{
Clinical relevance of contextual factors as triggers of placebo and nocebo effects in musculoskeletal pain
}

\author{
Giacomo Rossettini ${ }^{1}$, Elisa Carlino ${ }^{2}$ and Marco Testa ${ }^{1 *}$ (1)
}

\begin{abstract}
Placebo and nocebo effects are embodied psycho-neurobiological responses capable of modulating pain and producing changes at different neurobiological, body at perceptual and cognitive levels. These modifications are triggered by different contextual factors (CFs) presented in the therapeutic encounter between patient and healthcare providers, such as healing rituals and signs. The CFs directly impact on the quality of the therapeutic outcome: a positive context, that is a context characterized by the presence of positive CFs, can reduce pain by producing placebo effects, while a negative context, characterized by the presence of negative CFs, can aggravate pain by creating nocebo effects. Despite the increasing interest about this topic; the detailed study of CFs as triggers of placebo and nocebo effects is still lacked in the management of musculoskeletal pain.

Increasing evidence suggest a relevant role of CFs in musculoskeletal pain management. CFs are a complex sets of internal, external or relational elements encompassing: patient's expectation, history, baseline characteristics; clinician's behavior, belief, verbal suggestions and therapeutic touch; positive therapeutic encounter, patient-centered approach and social learning; overt therapy, posology of intervention, modality of treatment administration; marketing features of treatment and health care setting. Different explanatory models such as classical conditioning and expectancy can explain how CFs trigger placebo and nocebo effects. CFs act through specific neural networks and neurotransmitters that were described as mediators of placebo and nocebo effects.

Available findings suggest a relevant clinical role and impact of CFs. They should be integrated in the clinical reasoning to increase the number of treatment solutions, boosts their efficacy and improve the quality of the decision-making. From a clinical perspective, the mindful manipulation of CFs represents a useful opportunity to enrich a well-established therapy in therapeutic setting within the ethical border. From a translational perspective, there is a strong need of research studies on CFs close to routine and real-world clinical practice in order to underline the uncertainty of therapy action and help clinicians to implement knowledge in daily practice.
\end{abstract}

Keywords: Placebo, Nocebo, Contextual factors, Clinical reasoning, Pain, Expectation, Conditioning, Learning, Therapeutic encounter, Therapeutic relationship

\footnotetext{
*Correspondence: marco.testa@unige.it

${ }^{1}$ Department of Neuroscience, Rehabilitation, Ophthalmology, Genetics,

Maternal and Child Health, University of Genova, Campus of Savona. Via

Magliotto, 2, 17100 Savona, Italy

Full list of author information is available at the end of the article
} 


\section{Background}

Pain represents a "distressing experience associated with actual or potential tissue damage with sensory, emotional, cognitive and social components" [1]. Among the different pain conditions, musculoskeletal pain is ubiquitous and multifaceted: it can be the consequence of everyday activities that repeatedly or unusually stress the system, or it can be due to either acute traumatic events or to musculoskeletal diseases [2]. It is the most disabling symptom in musculoskeletal disorders, causing a high number of requests for healthcare treatments and rising social costs [3]. Moreover, especially in chronic conditions when pain persists beyond the normal healing time, it is influenced by different physical, psychological and social factors [4-6] defined as "contextual factors" (CFs).

The multidimensionality that characterizes pain in musculoskeletal complaints requires an integrative and personalized approach for its treatment. For this reason, the study of the CFs and their conscious use and integration in the clinical practice could represent a novel approach in the management of this complex experience [7-16].

By definition, CFs are physical, psychological and social elements that characterize the therapeutic encounter with the patient $[17,18]$. CFs are actively interpreted by the patient and are capable of eliciting expectations, memories and emotions that in turn can influence the health-related outcome, producing placebo or nocebo effects [19]. In other words, the CFs represent the context that accompany any healthcare treatment: the exposure of a patient to a positive context (positive CFs) very often produces a placebo effect that is the occurrence of symptoms improvement (e.g. analgesia), whereas a negative context (negative CFs) can generate a nocebo effect, with a worsening of the pain condition (e.g. hyperalgesia) [20, 21]. In the following review, we use the term CFs instead of placebo, avoiding the misleading interpretation of placebo as inert treatment given to comfort or please the patient and following the recent conceptualization of the placebo as the psychosocial context that accompanies any medical intervention, be it active or sham [22-31].

As extensively demonstrated by the placebo and nocebo effect literature, the CFs can affect the outcome of a treatment with different mechanisms and in different systems, medical conditions, and therapeutic interventions [32]. From a clinical perspective, the study of CFs as triggers of placebo and nocebo effects, is crucial for the management of musculoskeletal pain for several reasons [33]. First, even if CFs are embodied in every complex therapeutic interventions in musculoskeletal complaints, they are often considered as incidental factors capable to affect outcomes. For this reason they are not always identified and used intentionally by clinicians
[34]. Second, CFs can produce a therapeutic effect through the involvement of the same central pathways of pain modulation activated by several hands-on (e.g. manual therapy, therapeutic exercises, acupuncture, injections) and hands-off solutions (e.g. pain neuroscience education) commonly applied in clinical practice [35-37]. Third, CFs serve as additional tools for the interpretation of the clinical picture and guide clinicians in managing the complexity behind the patient's musculoskeletal pain [38]. Taking into consideration CFs as active influencer of the therapeutic outcomes, can help to explain some unexpected outcomes and variability of symptoms experience [39].

Moving from this vision, the present debate is proposed to all the health professionals (physiotherapists, chiropractors, osteopaths, nurses, occupational therapists, rheumatologists, orthopedics etc.) that work with musculoskeletal pain. In order to support a better and more conscientious therapeutic use of the CFs in musculoskeletal field, the purposes of this debate are to: 1) briefly define the CFs, how they work and act from a neurophysiological perspective; 2) underline their clinical relevance in pain management; 3) consider their role in clinical reasoning, within the ethical border and 4) suggest how to take them into account in the research field.

\section{Contextual factors}

\section{What do the contextual factors represent?}

A treatment is never administered in a neutral situation, but rather in a complex set of CFs, that Balint called the "atmosphere around the treatment" [40] and Miller and Kaptchuk called "contextual healing" [41]. Following these definitions, it is clear that the CFs can act "independently" by the nature of the treatment: since they represent the context of any medical treatment, they have a role when a sham treatment is administered but also when an active treatment is administered.

CFs were introduced in 2001 by Di Blasi et al. [17] in medical community and recently exploited by Testa \& Rossettini in physiotherapy field [33]. CFs can be internal, external or relational. The internal factors consist of memories, emotions, expectations and psychological characteristics of the patient; the external factors include the physical aspects of therapy, such as the kind of treatment (pharmacological or manual) and the place in which the treatment is delivered. Relational factors are represented by all the social cues that characterizes the patient-physiotherapist relationship, such as the verbal information that the physiotherapist gives to the patient, the communication style or the body language [19].

A clear identification of the CFs is crucial in clinical practice, in order to enhance the treatment efficacy. In a work targeted to physiotherapy field, CFs have been grouped in 5 different categories on the base of their 
sensory and social features [33]: physiotherapist characteristics (professional reputation, appearance, beliefs, behaviours); patient characteristics (expectation, preferences, previous experience, musculoskeletal condition, gender, age); patient-physiotherapist relationship (verbal communication, non-verbal communication), treatment (clear diagnosis, overt therapy, observational learning, patient-centered approach, global process of care, therapeutic touch), healthcare setting (environment, architecture, interior design).

During any clinical phase (e.g. consultation, examination and treatment) the CFs "inform" the patient that a healthcare procedure has been delivered and they could positively or negatively affect symptom perception, experience and meaning $[20,21]$.

The identification of the CFs and the attention to healthcare context is crucial for at least two reasons. First, a treatment delivered in a positive context (positive $\mathrm{CFs}$ ) produces better outcomes than a treatment delivered in a neutral condition or negative context (negative CFs). The open-hidden approach is one of the best evidence of decreased effectiveness of a medical treatment when a meaningful context is eliminated [42]. In the "open" condition, that mimics the routine medical practice, a treatment is delivered in full view of the patient: it means that the patient is aware of receiving a medical treatment and know when the medical treatment is delivered. In the "hidden" condition, the treatment is administered unbeknownst to the patient. Different studies have reported that open treatments are more effective than hidden treatments, because in the hidden condition the surrounding context (healing rituals, therapist-patient interaction, etc.) is absent, thus losing its positive meaning [43-46].

Second, the psychosocial context can influence the patients in different ways since the responsiveness to the context seems to be not a stable trait but a situational trait [47], and the same patient can sometimes positively respond to the context and sometimes not. Thus, if a patient is not influenced by the therapeutic context (the so called "placebo non-responders") he/she needs more medical attention because the lower the placebo responsiveness, the lower the treatment responsiveness [48]. Indeed, if the total treatment effect is conceptualized as the sum of the CFs effect plus the active treatment effect plus the interaction of the CFs and active treatment effects [49], a patient that is not sensible to the positive influence of the CFs will show a lower treatment response [50].

\section{How do the contextual factors trigger placebo and nocebo effects?}

If we aim to implement an aware use of CFs along the clinical routine, the understanding of how they work has a capital importance. The CFs shape placebo and nocebo effects through different sources. Historically, the most important models include classical conditioning and expectation processes.

Following the classical conditioning, different external CFs represent an example of conditioned stimuli that evoke a conditioned response [51]. In general, as proposed by this model, the repeated contingency between a salient unconditioned stimulus (e.g., sight of food) with a neutral conditioned stimulus (e.g., a bell ringing) can induce the same conditioned response (i.e., salivation) even if the neutral stimulus is presented alone. In the specific contest of healthcare, different aspects of the healthcare setting or physical features of the medical treatment can act as external conditioned stimuli, eliciting a therapeutic response in the absence of an active principle, just because they have been previously associated with it. Recently, other learning mechanisms has been documented, such social learning. In particular, beyond direct first-hand experience to specific external $\mathrm{CFs}$, it is possible to learn a conditioned response by observing other people that respond to specific CFs [9].

Following the expectation model, different external, internal and relational CFs can activate the expectancy of pain relief, triggering neurobiological changes and symptoms' amelioration [52]. Verbal suggestions are typical external CFs that trigger positive or negative responses. For example, the administration of an analgesic treatment along with the expectations of pain relief can lead to a positive analgesic response, whereas the administration of an analgesic treatment without specific expectations or with expectations or pain exacerbation can result in a negative response and in the perpetration of pain [53].

Following the Colloca and Miller integrative model [54], conditioning and expectations are not mutually exclusive and can be integrated in a more general learning model, whereby various types of CFs trigger expectancies, memories and emotions that in turn generate behavioral and clinical outcome changes, through the activation of the central nervous system (Fig. 1) [7, 9, 20, 21]. In other words, the presence of external CFs, combined with specific internal and relational CFs, is interpreted by the patient and converted into neural input events and behavioral changes [54]. This model represents a good conceptualization of the role of the therapeutic context, useful also at the clinical practice level. Indeed, it opens up to the possibility to study the effects and the impacts of every single CF on the outcome of a medical treatment.

\section{How do the contextual factors work at the neurobiological level?}

A robust body of knowledge, especially acquired in the field of pain, has identified the neural networks activated by the CFs. Indeed, a crucial question that catch the 


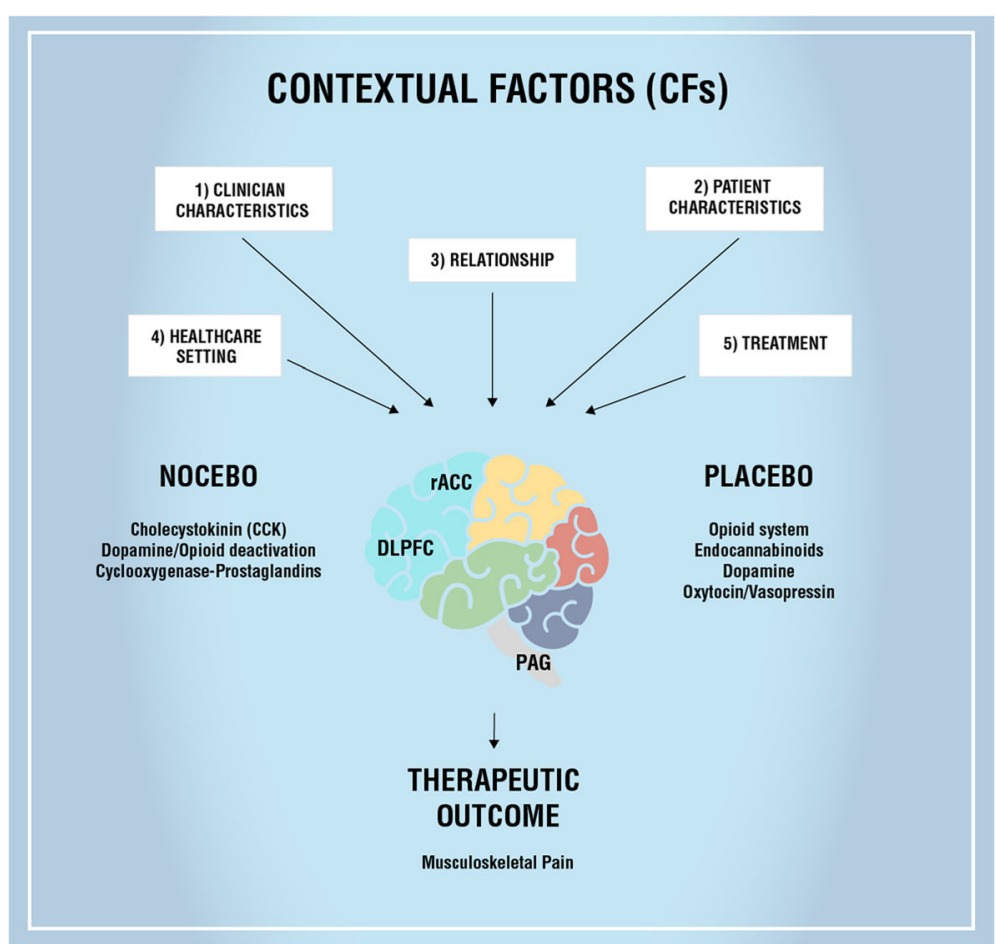

Fig. 1 Psycho-neurobiological mechanism of CFs. The image displays how CFs are capable to influence the brain networks, neurochemistry and therapeutic outcome. The principal neural areas and neurotransmitters involved in placebo and nocebo effects are reported. Abbreviation: rACC $=$ Rostral Anterior Cingulate Cortex; DLPFC = Dorsolateral prefrontal cortex; PAG = Periaqueductal gray

attention of neuroscientists and clinicians is whether the subjective changes in the outcome after the exposure to a specific therapeutic context are associated with specific neurobiological activities [10]. Pharmacological studies, as well as neuroimaging studies, have address this question using different experimental approaches based on classical conditioning and modulation of expectations. Taken together, these studies demonstrated that different changes in the pain processing network occurs when positive or negative CFs trigger placebo or nocebo effects, respectively. In particular, pain reduction is associated with decreased activity in the classical pain-matrix areas, such as the thalamus, insula, somatosensory cortex, and mid-cingulate regions [55-60]. Interestingly, positron emission tomography (PET) studies showed that the analgesic effect induced by the administration of a real mu-agonist, such as remifentanil, and the analgesic effect triggered by verbal suggestions determined similar activation of different brain regions, such as rostral anterior cingulate cortex and the orbital cortex $[61,62]$. Separating the pain anticipation phase and the pain perception phase, a meta-analysis of brain imaging data using the activation likelihood estimation method, identified the involvement of different brain regions: during expectation, areas of activation are found in the anterior cingulate, precentral and lateral prefrontal cortex, and in the periaqueductal gray, whereas during pain inhibition, deactivations are found in the mid- and posterior cingulate cortex, superior temporal and precentral gyri, in the anterior and posterior insula, in the claustrum and putamen, and in the thalamus and caudate body [63]. On the other hand, pain increase is associated with signal increases in several regions including anterior cingulate cortex, insula, left frontal and parietal operculum [64-67]. Also, high temporal resolution techniques, such as electroencephalography (EEG), have confirmed that the amplitude of specific evoked potentials, both related to pain anticipation and to pain perception, are affected by the CFs [68-71]. Thus, both early and late sensory components of pain processing are affected by the exposure to positive and negative CFs.

Different studies have also characterized the neurotransmitter systems activated the CFs. Using a classical conditioning approach, it has been demonstrated that when an opioid drug, such as morphine, is delivered for different days and then it is replaced by a placebo unbeknownst to the patient a placebo analgesic effect occurs [72]. This effect can be blocked by the mu opioid antagonist, naloxone, thus indicating that the opioid system plays an important role [57, 73, 74]. An indirect evidence of the involvement of the opioid system comes from the study of the anti-opioid action of the cholecystokinin (CCK) system. 
The proglumide, that is a CCK antagonist, enhances placebo analgesia $[75,76]$, whereas the activation of the CCK type- 2 receptors with the agonist pentagastrin disrupts it [77]. These pharmacological data have been confirmed by a neuroimaging study, in which the authors proved that naloxone blocked the placebo analgesic response in dorsolateral prefrontal cortex (DLPFC), rostral anterior cingulate cortex (rACC), hypothalamus, periaqueductal gray (PAG), and rostral ventromedial medulla (RVM), and abolished placebo-enhanced coupling between rACC and PAG [57]. Using a the same conditioning protocol, it has been demonstrated that also the cannabinoid system is activated by the positive therapeutic context: when non-opioid drugs, like ketorolac, are administered for 2 days in a row and then replaced with a placebo on the third day, the analgesic effect is not reversed by naloxone, whereas the CB1 cannabinoid receptor antagonist, rimonabant, blocks this placebo analgesia completely [78]. Also studies in which expectations were manipulated by positive verbal suggestions, showed an activation of $\mu$-opioid neurotransmission in the dorsolateral prefrontal cortex, the anterior cingulate cortex, the insula, and the nucleus accumbens $[79,80]$.

A different system activated by the therapeutic context is the dopaminergic system: indeed, the positive effect due to the presence of positive CFs seems to be related to the activation of dopamine in the nucleus accumbens. as assessed using in vivo receptor binding PET with raclopride. Moreover, when expectations of pain reduction were induced, the analgesic effect of the context was associated with activation of opioid neurotransmission in the anterior cingulate, orbitofrontal and insular cortices, nucleus accumbens, amygdala, and periaqueductal gray matter. Dopaminergic activation was observed in the ventral basal ganglia, including the nucleus accumbens. Both dopaminergic and opioid activity were associated with both anticipation and perceived effectiveness of the positive verbal suggestions [81, 82].

Recently, oxytocin [83] and vasopressin [84] have been identified CFs enhancer as they potentiate the analgesic effect due to the presence of positive verbal suggestions. Moreover it has been documented that negative expectations about headache pain led to the enhancement of the cyclooxygenase-prostaglandins pathway, which, in turn, induced pain worsening [85].

\section{Clinical relevance of the contextual factors} What is the magnitude of placebo and nocebo effects induced by CFs in musculoskeletal pain?

The impact of CFs as trigger of placebo and nocebo effects on pain outcome has been quantified in different ways and has been reported in a wide range of musculoskeletal conditions such as low back pain [86-108], neck pain $[95,99,109-111]$, shoulder pain $[95,112,113]$, osteoarthritis [38, 91, 99, 100, 114-125], rheumatoid arthritis [126], and fibromyalgia [97, 127-132].

Different studies have measured the magnitude of placebo and nocebo effects induced by CFs in different musculoskeletal pain conditions commonly encounter in daily setting [117, 133]. Indeed the clinical effectiveness of placebo analgesia was demonstrated in specific complaints such as fibromyalgia [128] and osteoarthritis [118] with an effect size (ES) over 0.5. Also, nocebo hyperalgesia measured as dropout rate due to adverse event were present in fibromyalgia (9.6\%) [134] and osteoarthritis (4.8\%) [135]. Concerning osteoarthritis, the ES decreased consistently from hand, to knee, to combined hip and knee and then to hip [118, 136].

Moreover, considering the overall treatment efficacy as the sum of the specific component related to the active treatment plus the unspecific component due to the CFs, the impact of the CFs was measured in different conditions and interventions [137]. Zou and colleagues showed that $75 \%$ of the overall treatment effect in osteoarthritis is attributable to contextual effects rather than the specific effect of treatments [116]. In fibromyalgia, the $45 \%$ of the response of the active drug is attributable to contextual effect [129] and a relevant contextual effects was shown also in aspecific low back pain [138]. Moreover, a recent meta-analysis on spinal manual therapies showed that in acute pain and chronic pain, respectively 81 and $66 \%$ of the pain variance were ascribed to CFs [139].

\section{Which kind of CFs influence musculoskeletal pain conditions?}

Considering the patient's perspective, expectations toward the therapy, patient's treatment history and baseline pain severity are elements capable to predict the outcomes of different musculoskeletal pain treatments.

Expectations of symptoms improvement can be activated by different CFs: for example, the simple act of administering a treatment, the exposure to a clinical setting, the verbal or non-verbal interaction with the physician are capable of triggering patient's expectations. As demonstrated by different studies, boosting patient's expectations toward the therapy significantly increased the chance of pain relief more than delivering a treatment without the expectation of any benefit [86, 90-98, 109, 111, 112, 126, 140].

Patient's treatment history, that is the patient's history of past positive or negative medical treatments, can influence the future response of the patient to new medical treatments. Previous positive experiences obtained by a specific therapy increase the likelihood of future positive experiences with the same therapy, while precedent negative outcomes associated to a particular 
intervention increase the probability of negative outcomes $[99,141]$.

Higher pain intensity at baseline $[99,100,118,128,129]$ and the presence of concomitant diseases and psychosocial elements such as depressions [99, 130] are associated with an augmented placebo analgesia and reduced nocebo hyperalgesia. Long-term dysfunction seems to respond less to placebo analgesia indicating that duration of complaints influence placebo analgesia $[128,132]$.

From the provider's perspective, clinician's behavior, belief, verbal suggestions and therapeutic touch can strongly influence patients' pain perception.

A provider acting as competent, experienced, educated, professional, trustworthy, capable to indicate a diagnosis and prognosis, and to monitor patient with follow up, can moderate pain with his behavior [38, 114, $115,120,142]$. Aligning his/her beliefs with patient's beliefs, a clinician could modulate pain. Indeed, it was demonstrated that the healthcare provider's point of view concerning the clinical pathway, the therapy and the prognosis influence patient's pain [38, 101-103, 107, $114,115,143,144]$. Informing the patient that a potent treatment has been delivered enhanced the analgesic effect of the treatment, conversely verbal suggestion concerning the threatening effect of the therapy can compromise the effectiveness of the treatment creating nocebo hyperalgesic effects $[108,121,122,141,145$, 146]. Non-verbal communication has powerful effects as well. For example, the use of therapeutic touch can positively influence patient's pain [105, 123, 124, 131, 147, 148].

Finally, considering the patient-physician relationship, it appears that a positive therapeutic encounter between patient and clinicians can lead to additional clinical benefits. Indeed, an enhanced empathetic interaction comprehensive of therapeutic alliance, active listening, extra time spent with patient, more face-to-face visit, warmth, attention, care, encouragement and support significantly reduced pain more than the same therapy performed with neutral therapeutic interaction $[87,88,100,104$, 145, 149, 150]. Moreover, a patient-centered approach can increase the effectiveness of the therapy. Indeed, the patient's involvement in the global process of care has been shown to modulate pain $[106,125]$. The strategy to favor the social learning between patients by the observation of other's pain improvement or reduction is capable to affect the observers' symptomatology [151, 152].

Also the way by which the therapy is administered can influence pain perception. The adoption of an overt paradigm that enhances patient's knowledge of being treated modulates the therapeutic outcome [110]: a significant pain reduction was observed after the execution of an exercise in an environment that allowed patients to visualize their body [89]. Also the posology of intervention has an effect as CFs: the placebo effect is higher when therapies are more frequent and repeated a therapy is delivered (e.g. two or more times vs one time) [118]. The choice of the modality of treatment administration can be crucial to modulate patient's pain. In general, the higher is the invasiveness of treatment (e.g. acupuncture, dry needling, injection, surgery), the better is the reduction of pain $[116,118,119,153,154]$. Moreover, parenteral or subcutaneous administrations (e.g. topical) are more efficient than oral administrations $[115,116,119]$.

Even the marketing features of treatment should be taken into account. Branded therapy seems to be more effective than unbranded therapy $[114,115]$. High prize medication produced better pain relief then discounted medication, therapy considered as "new" improved pain more than "usual" therapy $[114,115]$. The more complex is the procedure including therapeutic rituals, mysterious powers, high technology the larger the placebo effect $[114,115]$.

Lastly, the health care setting, in terms of environment, architecture and interior design should not be overlooked. The use of facilities where evidence-based design such as furnishing, colors, artwork, light, outside views, temperature, soothing sound and music were adopted, positively impacts on patient's pain creating a proper healing setting [127, 155-157].

\section{Clinical applications and translational research} Is it time to implement CFs in our clinical reasoning?

The clinical reasoning adopted by clinicians in musculoskeletal conditions represents a complex procedure that encompasses different dimensions of pain experience in a bio-psycho-social framework [158]. Indeed, this multifactorials thinking process considered biomedical (e.g. tissue pathology, disease), psychological and social elements (e.g. experience of disability, patient's belief, values and perspective) to obtain more complete analyses of the patient's dysfunction [159]. The role and the impact of CFs should be integrated in the clinical reasoning to increase the number of treatment solutions, boosts their efficacy and improve the quality of the decision-making [33]. Based on the evidence available, some considerations can be drawn to guide a more conscious use of CFs as activators of placebo analgesia and avoiders of nocebo hyperalgesia.

Considering the global process of care, clinicians should be aware that the overall therapeutic outcome is determined by the suitability of the therapy adopted ("what we do") and by how it is delivered ("how we do") [33]. In this perspective, every musculoskeletal pain treatment is composed by a specific component and by a contextual component [34]. These components represent the two faces of the same coin and are capable of influencing pain at multiple levels of the central nervous 
system [160]. The use of the best evidence-based therapy is unquestionable, but clinicians should not forget the role of the CFs, as the context surrounding the specific treatment is capable of generating placebo or nocebo responses and modifying the therapeutic trajectory towards a positive or a negative direction [42].

Because it is a fact that placebo [161-163] and nocebo [164] effects are always present in routine clinical practice and can be triggered by CFs [33], clinicians should be able to use them to optimize the results and reduce failures. Indeed, there are clear evidence that, when placebo was purposely searched as a mechanism, the effect size was about five times greater (Cohen's $d$ ranging from 0.95 to 1.14) [161-163] than when placebo was used as a control condition (Cohen's d ranging from 0.15 to 0.27) [165-167]. Moreover, clinicians should combine at the same time different CFs to obtain a larger placebo effect and minimize the nocebo effects. Some studies demonstrated that a lower effect size is present when using verbal suggestions alone (placebo - Cohen's d $=0.85$; nocebo - Cohen's $d=0.65$ ), while a higher effect size was observed adopting a combination of verbal suggestions and conditioning procedures (placebo - Cohen's $\mathrm{d}=1.45$; nocebo - Cohen's $\mathrm{d}=1.07)[161,164]$.
Since placebo effects are learning phenomenon [9], during the history taking, clinicians should assess the patient's previous experience, expectations and beliefs giving the patient adequate time to tell his/her story [50, 168, 169] (Fig. 2).

Previous successful and unsuccessful experiences of a specific treatment are capable to influence the therapeutic outcome [170]. In order to plan a therapeutic intervention, it's important to question about past memories of analgesic and hyperalgesic responses concerning a treatment; reinforcing the positive experiences and devaluating the negative ones $[7,169,171-173]$. For example, if a patient had a previous negative experience with a specific treatment, clinician should avoid adopting it. On the contrary, if a patient experienced a positive outcome with a treatment, the use of the very same treatment is recommended in order to "activate" the patient's positive memory of the previous treatment.

Since patients' expectations about the therapeutic benefit influence the effectiveness of the treatment, a clear assessment of patients' expectations toward the therapy is crucial. In particular, it is crucial to identify patients with low expectations in order to work with them with the aim of improving their belief [174].

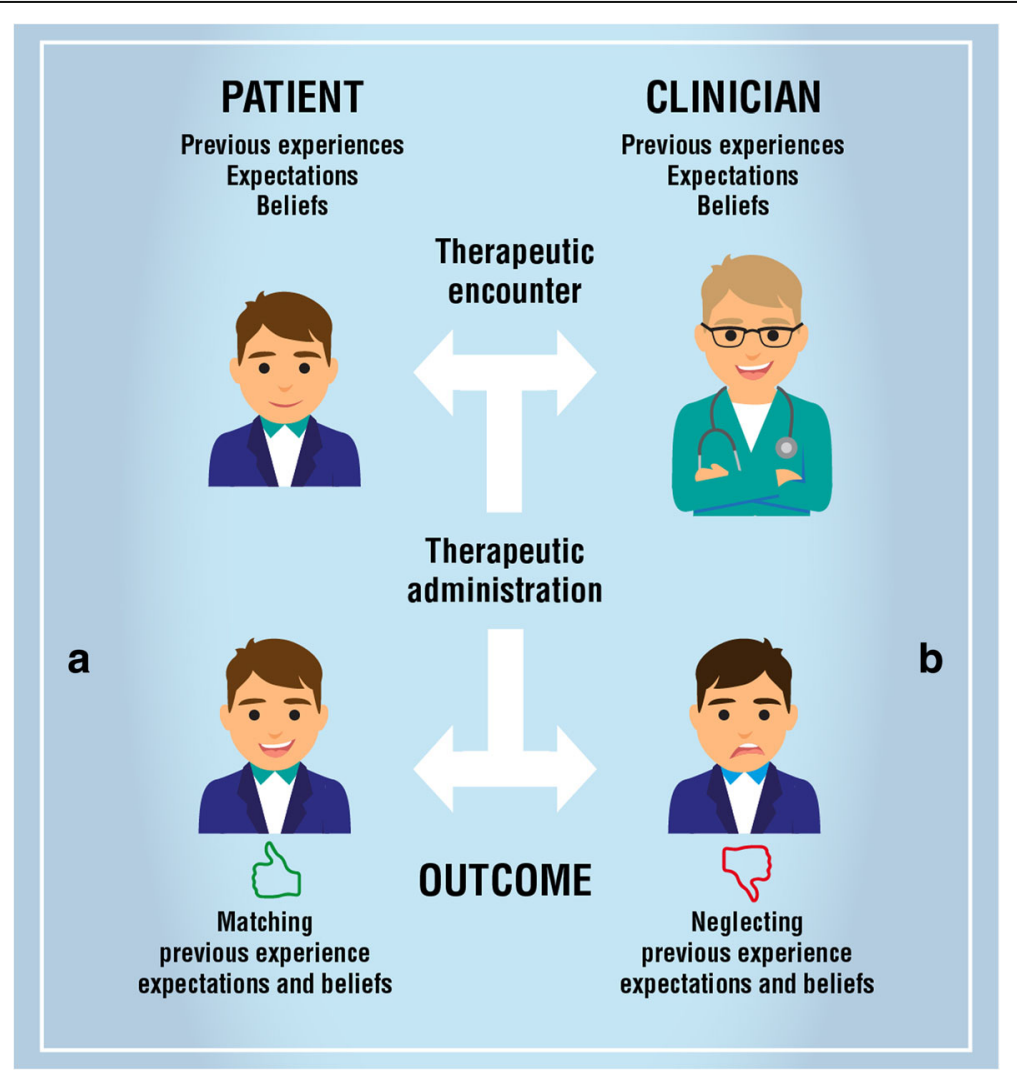

Fig. 2 Influencers of decision-making process. The image presents: a the clinical situation in which meeting patient's expectation, previous experience and beliefs creates positive therapeutic outcomes; $\mathbf{b}$ the clinical situation in which ignoring patient's expectation, previous experience and beliefs creates negative therapeutic outcomes 
Different scale and semi-standardized questionnaires have been proposed to assess patient's expectations. For example, Younger et al. developed a tool for measuring patient outcome expectancy. The authors found that the final six-item scales, made of two subscales (positive expectancy and negative expectancy), predicted a significant amount of outcome variance in patients receiving surgical and pain intervention [175].

Moreover, clinicians should monitor patient's belief concerning musculoskeletal conditions, therapeutic action, prognosis and ask questions about the meaning they attribute to symptoms $[169,172,176-178]$. In these times of important expansion of healthcare information delivering by Internet, social media and television it is crucial to avoid the misinformation [7]. The discussion with the patients can help the clinician to guide them to evidence-based information and avoid that they refer to unproven or fake information [176]. Also, asking systematically the patients to summarize the information provided can prevent negative misunderstandings about their complaints [169, 173, 176, 178].

In the waiting, examination, therapeutic and follow-up phases, the social interaction between patients $[179,180]$, the therapeutic ritual $[181,182]$ and the awareness of the ongoing procedure $[42,43]$ are fundamental elements to consider.
While waiting for healthcare encounter, a pleasant and peaceful environment, employing professional, friendly and helpful support staff can help patients to feel comfortable [169]. In waiting rooms, clinicians should reduce the social contagion of negative emotions preventing the patient's interaction and/or observation of another patient experiencing a negative outcome (e.g. increased pain) $[7,183]$. Instead, they should promote the social interaction favoring observation of the positive effects of the therapy (e.g reduction of pain) also using video clips showing patients coping well with painful condition [50, 176, 179, 180] (Fig. 3).

Before starting the treatment clinicians should read records, thoroughly examine the patients, provide a confident diagnosis and propose, when available, different treatment options encouraging the patient's involvement in the choice of therapy and treatment goals [169, 171, 184-186].

During treatment it is useful to avoid unintentional "hidden administration" of therapy [173]. Thus, it is crucial to focus the patient's attention to all the salient sensory elements presented in the therapeutic arena in order to increase the contextual power of the therapy [169]. These elements are: the healthcare environment (e.g. light, color, design of the room), the physical features of the therapy (e.g. shape, size, colour, smell and

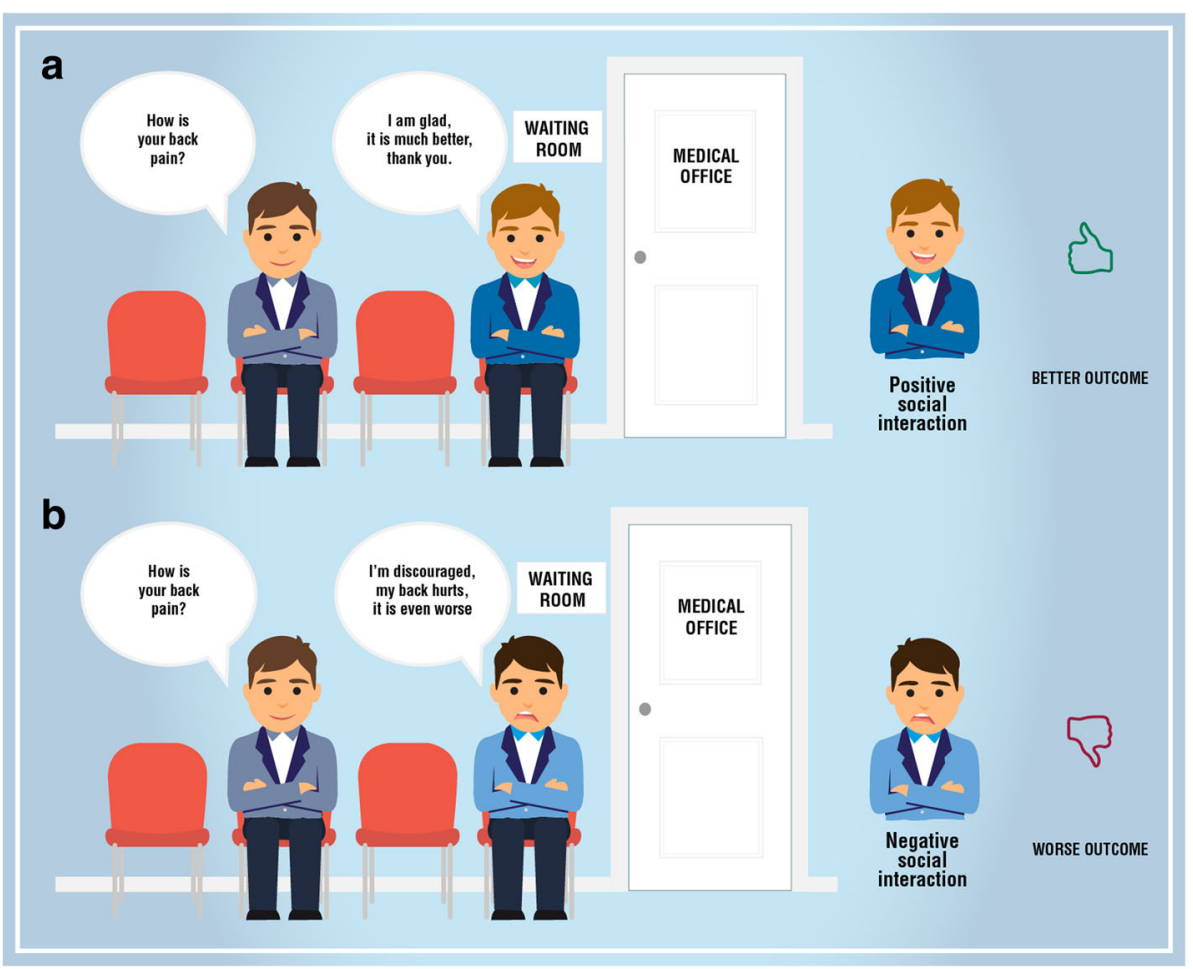

Fig. 3 Social interaction and learning. The image displays: a a positive social interaction between patients in waiting room capable to produce positive therapeutic outcome; $\mathbf{b}$ a negative social interaction between patients in waiting room capable to produce negative therapeutic outcome 
taste) and the technological features of the device (e.g. novelty, price, invasiveness) [50, 169-173, 187] (Fig. 4).

After the treatment, it is valuable to assess the therapeutic outcome and give to patient a feedback on the clinical course in order to maximize the treatment adherence, encouraging the self-managing of the condition $[50,169]$.

The clinician's not-verbal and verbal communication represent important element of the overall clinical interaction [33].

Clinicians should prepare themselves mentally and physically for the clinical encounter [38], acting as experts in their field $[169,172]$. It is crucial to effectively inform about the efficacy of a specific treatment $[169,172]$, considering that beliefs and behaviors could influence patients' attitudes in a positive or negative way [7, 169]. It is suitable to individualize consultation style according to the patient's preference opting for a personal interaction and seeking for a warm, authentic and empathic style, limiting technical contacts to the minimum [169, 171, 172, 176, 188-190].

Also, the content of the message (what), the modality of delivering (how) and the time of communication (when) represent a great clinical enigma [191] and should be taken into account. It is recommended to enhance the positive expectation toward the treatment and limit the emphasis on contraindications, tell patients about side effects, but associated with positive clinical outcome. Side effects of treatment should be presented in form of probability instead of a mere list and during the informed consent process positive and negative information should be balanced $[7,50,169,172,173$, 176, 180, 183, 191, 192].

\section{What is the concern about ethics?}

The adoption of placebo strategies seems to be common practice in clinical routine among healthcare providers [193]. In musculoskeletal field, orthopedics surgeon, rheumatology physicians and nurses thought that placebo effects are real, have therapeutic benefits, and are permissible within the ethical borders [194-196]. Patients with chronic musculoskeletal pain and rheumatologic complaints know what placebo effects are, consider placebo treatments acceptable when adopted as complementary/adjunct treatments and when no other established treatments are available. However, they present a lack of understanding of nocebo effects [196-198]. Scientific community is still focusing the debate on the possibility of a transparent disclosure to patients of placebo treatments [199-202]. The current researches suggest the possibility to openly prescribe sham medication or sham physical treatments with advanced prior consent [169]. Thus, when available the choice of the best evidence-based therapy is mandatory and a patient must be informed about the use of a placebo

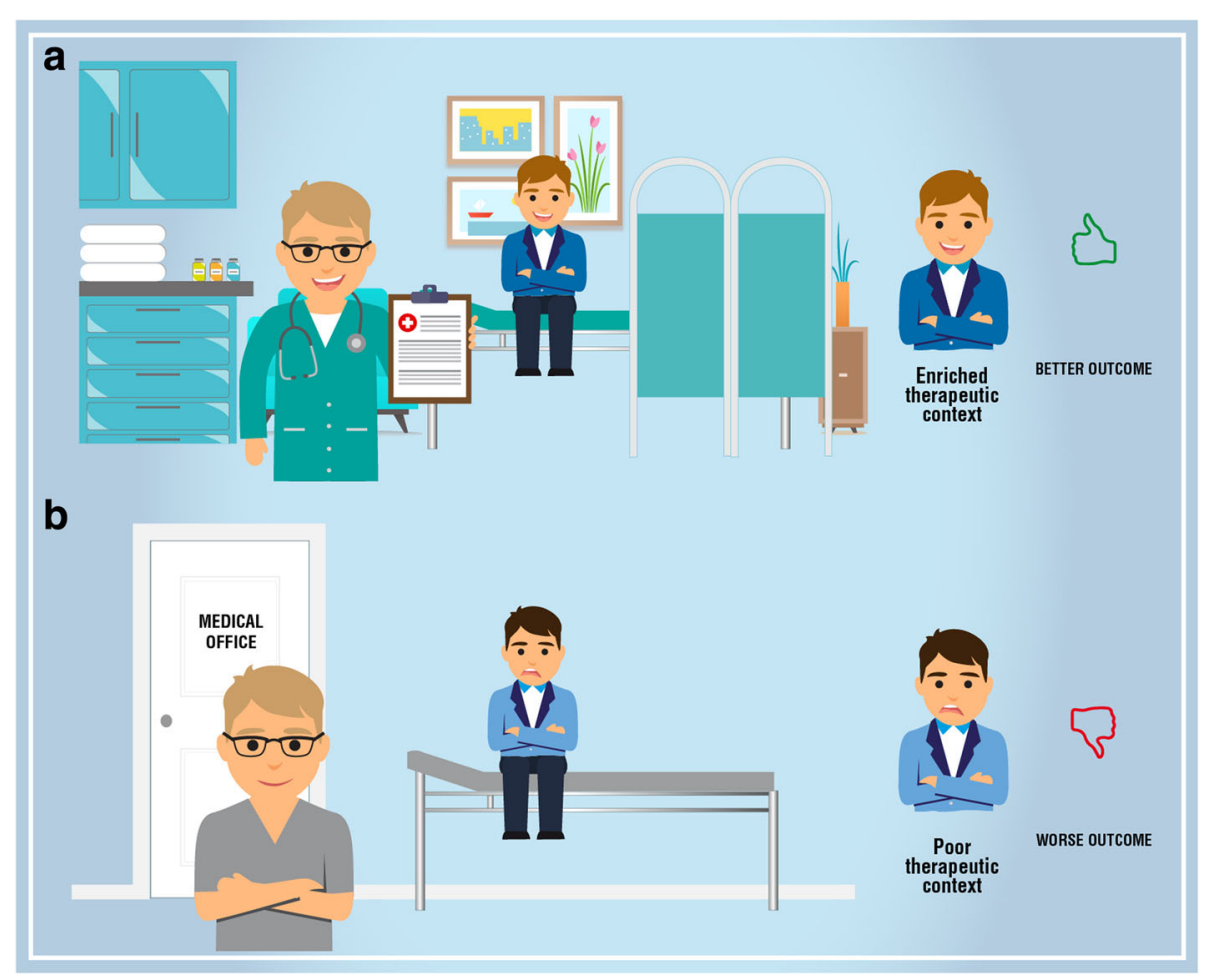

Fig. 4 Therapeutic rituals and overt therapeutic administration. The image displays: a an enrich therapeutic context capable to produce positive therapeutic outcome; $\mathbf{b}$ a poor therapeutic context capable to produce negative therapeutic outcome 
intervention with an amount of disclosure sufficient to avoid deception [201, 203, 204]. Although it is common thought that revealing the use of a placebo inhibits its effect, different studies point out the efficacy of placebo interventions also in "open label" conditions where the use of a placebo was disclosed in patients with chronic low back pain $[205,206]$. From a clinical perspective, the mindful manipulation of CFs represents a useful opportunity to enrich a well-established therapy that have different ethical implication in comparison with the replacement of real treatment with a potentially ineffective treatment [200].

\section{Is there a place for a translational research on CFs?}

There is a strong need of research studies on CFs close to routine and real-world clinical practice $[49,207]$ in order to underline the uncertainty of therapy action [208] and help clinicians to implement knowledge in daily practice.

The research community should investigate the effect of the different CFs on therapeutic outcome, instead of minimizing or labeling them exclusively as confounders $[209,210]$. The search for a good placebo control in musculoskeletal pain field (e.g. physical therapy) represents an unresolved challenge [211, 212]. Indeed, medical treatments are generally more complex than the mere administration of a drug, involving multiple treatment components that interact with each other and that are difficult to separate (e.g. verbal instruction and education, patient-therapist contact, physical action by the patient or therapist, and sensory feedback) leading to biased estimates of treatment effect [213].

In clinical trial there is a urge to measure patient's expectation before, during, and after the treatment [214] evaluating by standardized and validated scale all the dimensions of expectation (optimism, pain catastrophizing, hope, trust, worry and neuroticism) [215, 216]. Also measuring the impact of CFs from the patient's perspective represents a desirable outcome to be implemented in the future researches. Recently, a new item banks (Healing Encounters and Attitudes Lists - HEAL) was proposed as suitable for measuring CFs of the treatment and present promising evidence of predictive and concurrent validity [217].

Despite CFs play a key role in pain [20,21], there is a still paucity of knowledge on their effects in different musculoskeletal diseases, in young and old participants [218-220], in acute and chronic conditions [141], in different pain mechanism such as nociceptive, neuropathic, central sensitization [221]. It is of paramount importance to try to identify psychological, neuroendocrine or genetic elements that predict the responsiveness to specific CFs [50]. Finally, the use of meta-analysis may help to estimate the effects of the CFs [222].

\section{Limitations}

This debate presents some limitations. The framework adopted $[17,33]$ for reviewing the role of the CFs was not preliminarily validated for its specific consistency in the musculoskeletal field and some factors are not related exclusively to musculoskeletal pain literature but refer to pain in general. Examples of primary studies and data offered to sustain each factors of the model were not selected by adopting a systematic review approach and not criticized in depth, given that the main goal was to propose a short synopsis. CFs have been categorized into a conceptual framework by describing each factor involved, therefore interpretations about the relationships between factors and placebo/nocebo effects need additional critical analysis and discussion.

\section{Conclusion}

This debate points to a conscious use of the CFs, as supplementary therapeutic strategy for pain management capable to improve analgesia and prevent hyperalgesia. The good news is that pain perception can be positively influenced by an honest and aware use of CFs. The bad news is related to the complexity of the phenomenon, to a certain degree of uncertainty in the individual response and to a risk of patient's deception associated with their use. Nevertheless, clinicians have already enough comprehensive scientific information that allows them to choose the correct behavior wisely and adjust the CFs of the therapeutic setting in an evidence-based and ethically respectful perspective. We think that time has come for clinicians to manage conscientiously and ethically the CFs to enhance the placebo and avoid nocebo effects for the benefit of their patients.

\section{Abbreviations}

CCK: Cholecystokinin; CFs: Contextual factors; DLPFC: Dorsolateral prefrontal cortex; EEG: Electroencephalography; ES: Effect size; PAG: Periaqueductal gray; PET: Positron emission tomography; rACC: Rostral anterior cingulate cortex; RVM: Rostral ventromedial medulla

\section{Acknowledgements}

The authors want to thanks: Tommaso Geri and Marco Minacci for their valuable advices in the progression of this manuscript; Hassel

Comunicazione for their help during creation of images; the reviewers for their precious and constructive suggestions.

\section{Funding}

The authors declare that they don't use any external funding.

\section{Availability of data and materials}

Not applicable.

\section{Authors' contributions}

GR: made substantial contributions to conception and design, been involved in drafting the manuscript and revising it critically for important intellectual content, given final approval of the version to be published; agreed to be accountable for all aspects of the work in ensuring that questions related to the accuracy or integrity of any part of the work are appropriately

investigated and resolved; EC: made substantial contributions to conception and design, been involved in drafting the manuscript and revising it critically for important intellectual content, given final approval of the version to be 
published; agreed to be accountable for all aspects of the work in ensuring that questions related to the accuracy or integrity of any part of the work are appropriately investigated and resolved; MT: made substantial contributions to conception and design, been involved in drafting the manuscript and revising it critically for important intellectual content, given final approval of the version to be published; agreed to be accountable for all aspects of the work in ensuring that questions related to the accuracy or integrity of any part of the work are appropriately investigated and resolved. All authors read and approved the final manuscript.

\section{Ethics approval and consent to participate}

Not applicable.

\section{Consent for publication}

Not applicable.

\section{Competing interests}

The authors declare that they have no competing interests.

\section{Publisher's Note}

Springer Nature remains neutral with regard to jurisdictional claims in published maps and institutional affiliations.

\section{Author details}

'Department of Neuroscience, Rehabilitation, Ophthalmology, Genetics, Maternal and Child Health, University of Genova, Campus of Savona. Via Magliotto, 2, 17100 Savona, Italy. ²Department of Neuroscience, University of Turin Medical School, Turin, Italy.

\section{Received: 3 August 2017 Accepted: 15 January 2018}

Published online: 22 January 2018

\section{References}

1. Williams AC, Craig KD. Updating the definition of pain. Pain. 2016;157(11): 2420-3.

2. $\quad$ Dieppe P. Chronic Musculoskeletal Pain. BMJ. 2013:346:f3146.

3. Woolf AD, Erwin J, March L. The need to address the burden of musculoskeletal conditions. Best Pract Res Clin Rheumatol. 2012;26(2): $183-224$.

4. Gerdle B, Ghafouri B, Ernberg M, Larsson B. Chronic musculoskeletal pain: review of mechanisms and biochemical biomarkers as assessed by the microdialysis technique. J Pain Res. 2014;7:313-26.

5. lannetti GD, Mouraux A. From the neuromatrix to the pain matrix (and back). Exp Brain Res. 2010;205(1):1-12

6. Pelletier R, Higgins J, Bourbonnais D. Is neuroplasticity in the central nervous system the missing link to our understanding of chronic musculoskeletal disorders? BMC Musculoskelet Disord. 2015:16:25.

7. Blasini M, Corsi N, Klinger R, Colloca L. Nocebo and pain: an overview of the psychoneurobiological mechanisms. PAIN Rep. 2017;2(2):e585.

8. Vase L, Skyt I, Hall KT. Placebo, nocebo, and neuropathic pain. Pain. 2016; 157(Suppl 1):S98-105.

9. Colagiuri B, Schenk LA, Kessler MD, Dorsey SG, Colloca L. The placebo effect: from concepts to genes. Neuroscience. 2015;307:171-90.

10. Schedlowski M, Enck P, Rief W, Bingel U. Neuro-bio-behavioral mechanisms of placebo and Nocebo responses: implications for clinical trials and clinical practice. Pharmacol Rev. 2015;67(3):697-730.

11. Colloca $L$, Klinger R, Flor H, Bingel U. Placebo analgesia: psychological and neurobiological mechanisms. Pain. 2013;154(4):511-4.

12. Colloca L, Enck P, DeGrazia D. Relieving pain using dose-extending placebos: a scoping review. Pain. 2016;157(8):1590-8.

13. Belcher AM, Ferre $S$, Martinez PE, Colloca L. Role of placebo effects in pain and neuropsychiatric disorders. Prog Neuro-Psychopharmacol Biol Psychiatry. 2017;17:30164-1.

14. Colloca L, Miller FG. The nocebo effect and its relevance for clinical practice. Psychosom Med. 2011;73(7):598-603.

15. Benedetti F. Placebo effects: from the neurobiological paradigm to translational implications. Neuron. 2014;84(3):623-37.

16. Benedetti F, Lanotte M, Lopiano L, Colloca L. When words are painful: unraveling the mechanisms of the nocebo effect. Neuroscience. 2007; 147(2):260-71.
17. Di Blasi Z, Harkness E, Ernst E, Georgiou A, Kleijnen J. Influence of context effects on health outcomes: a systematic review. Lancet. 2001;357(9258):757-62.

18. Benedetti F. Placebo and the new physiology of the doctor-patient relationship. Physiol Rev. 2013;93(3):1207-46.

19. Wager TD, Atlas LY. The neuroscience of placebo effects: connecting context, learning and health. Nat Rev Neurosci. 2015;16(7):403-18.

20. Carlino E, Frisaldi E, Benedetti F. Pain and the context. Nat Rev Rheumatol. 2014;10(6):348-55.

21. Carlino E, Benedetti F. Different contexts, different pains, different experiences. Neuroscience. 2016;338:19-26.

22. Geuter S, Koban L, Wager TD. The cognitive neuroscience of placebo effects: concepts, predictions, and physiology. Annu Rev Neurosci. 2017; 40:167-88.

23. Doering BK, Rief W. Utilizing placebo mechanisms for dose reduction in pharmacotherapy. Trends Pharmacol Sci. 2012;33(3):165-72.

24. Buchel C, Geuter S, Sprenger C, Eippert F. Placebo analgesia: a predictive coding perspective. Neuron. 2014;81(6):1223-39.

25. Shaibani A, Frisaldi E, Benedetti F. Placebo response in pain, fatigue, and performance: possible implications for neuromuscular disorders. Muscle Nerve. 2017;56(3):358-67.

26. Schafer SM, Geuter S, Wager TD. Mechanisms of placebo analgesia: a dualprocess model informed by insights from cross-species comparisons. Prog Neurobiol. 2018;160:101-22.

27. Lucassen P, Olesen F. Context as a drug: some consequences of placebo research for primary care. Scand J Prim Health Care. 2016;34(4):428-33.

28. Manchikanti L, Boswell MV, Kaye AD, Helm li S, Hirsch JA. Therapeutic role of placebo: evolution of a new paradigm in understanding research and clinical practice. Pain Physician. 2017;20(5):363-86

29. Carlino E, Pollo A, Benedetti F. Placebo analgesia and beyond: a melting pot of concepts and ideas for neuroscience. Curr Opin Anaesthesiol. 2011:24(5):540-4.

30. Geers AL, Miller FG. Understanding and translating the knowledge about placebo effects: the contribution of psychology. Curr Opin Psychiatry. 2014; 27(5):326-31.

31. Tracey I. Getting the pain you expect: mechanisms of placebo, nocebo and reappraisal effects in humans. Nat Med. 2010;16(11):1277-83.

32. Benedetti F, Carlino E, Pollo A. How placebos change the patient's brain. Neuropsychopharmacology. 2011;36(1):339-54.

33. Testa M, Rossettini G. Enhance placebo, avoid nocebo: how contextual factors affect physiotherapy outcomes. Man Ther. 2016;24:65-74.

34. Paterson C, Dieppe P. Characteristic and incidental (placebo) effects in complex interventions such as acupuncture. BMJ. 2005;330(7501):1202-5.

35. Bishop M, Torres-Cueco R, Gay CW, Lluch-Girbés E, Beneciuk JM, Bialosky JE. What effect can manual therapy have on a patient's pain experience? Pain Manag. 2015;5(6):455-64.

36. Bialosky JE, Bishop MD, Price DD, Robinson ME, George SZ. The mechanisms of manual therapy in the treatment of musculoskeletal pain: a comprehensive model. Man Ther. 2009;14(5):531-8.

37. Bialosky JE, Beneciuk JM, Bishop MD, Coronado RA, Penza CW, Simon CB, George SZ. Unraveling the mechanisms of manual therapy: modeling an approach. J Orthop Sports Phys Ther. 2018;48(1):8-18.

38. Dieppe P, Goldingay S, Greville-Harris M. The power and value of placebo and nocebo in painful osteoarthritis. Osteoarthr Cartil. 2016;24(11):1850-7.

39. O'Sullivan P, Caneiro JP, O'Keeffe M, O'Sullivan K. Unraveling the complexity of low back pain. J Orthop Sports Phys Ther. 2016;46(11):932-7.

40. Balint M. The doctor his patient and the illness. Lancet. 1955:265(6866):683-8.

41. Miller FG, Kaptchuk TJ. The power of context: reconceptualizing the placebo effect. J R Soc Med. 2008;101(5):222-5.

42. Benedetti F, Carlino E, Pollo A. Hidden administration of drugs. Clin Pharmacol Ther. 2011;90(5):651-61.

43. Colloca L, Lopiano L, Lanotte M, Benedetti F. Overt versus covert treatment for pain, anxiety, and Parkinson's disease. Lancet Neurol. 2004;3(11):679-84.

44. Benedetti F, Maggi G, Lopiano L, Lanotte M, Rainero I, Vighetti S, Pollo A: Open versus hidden medical treatments: the patient's knowledge about a therapy affects the therapy outcome. Prevention Treatment 2003, 6(1):No Pagination Specified.

45. Benedetti F, Colloca L, Lanotte M, Bergamasco B, Torre E, Lopiano L. Autonomic and emotional responses to open and hidden stimulations of the human subthalamic region. Brain Res Bull. 2004;63(3):203-11.

46. Amanzio M, Pollo A, Maggi G, Benedetti F. Response variability to analgesics: a role for non-specific activation of endogenous opioids. Pain. 2001;90(3):205-15 
47. Horing B, Weimer K, Muth ER, Enck P. Prediction of placebo responses: a systematic review of the literature. Front Psychol. 2014;5:1079.

48. Benedetti F, Frisaldi E, Carlino E, Giudetti L, Pampallona A, Zibetti M, Lanotte M, Lopiano L. Teaching neurons to respond to placebos. J Physiol. 2016; 594(19):5647-60

49. Vase L, Amanzio M, Price DD. Nocebo vs. placebo: the challenges of trial design in analgesia research. Clin Pharmacol Ther. 2015;97(2):143-50.

50. Enck $P$, Bingel $U$, Schedlowski $M$, Rief $W$. The placebo response in medicine: minimize, maximize or personalize? Nat Rev Drug Discov. 2013;12(3):191-204.

51. Wickramasekera I. A conditioned response model of the placebo effect predictions from the model. Biofeedback Self Regul. 1980;5(1):5-18.

52. Kirsch I. Response expectancy as a determinant of experience and behavior. Am Psychol. 1985;40(11):1189-202.

53. Bingel U, Wanigasekera V, Wiech K, Ni Mhuircheartaigh R, Lee MC, Ploner M, Tracey I. The effect of treatment expectation on drug efficacy: imaging the analgesic benefit of the opioid remifentanil. Sci Transl Med. 2011;3(70):70ra14.

54. Colloca L, Miller FG. How placebo responses are formed: a learning perspective. Philos Trans R Soc Lond Ser B Biol Sci. 2011;366(1572):1859-69.

55. Wager TD, Rilling JK, Smith EE, Sokolik A, Casey KL, Davidson RJ, Kosslyn SM, Rose RM, Cohen JD. Placebo-induced changes in FMRI in the anticipation and experience of pain. Science. 2004;303(5661):1162-7.

56. Bingel U, Lorenz J, Schoell E, Weiller C, Buchel C. Mechanisms of placebo analgesia: rACC recruitment of a subcortical antinociceptive network. Pain. 2006;120(1-2):8-15.

57. Eippert F, Bingel U, Schoell ED, Yacubian J, Klinger R, Lorenz J, Buchel C. Activation of the opioidergic descending pain control system underlies placebo analgesia. Neuron. 2009;63(4):533-43.

58. Lui F, Colloca L, Duzzi D, Anchisi D, Benedetti F, Porro CA. Neural bases of conditioned placebo analgesia. Pain. 2010;151(3):816-24.

59. Elsenbruch $S$, Kotsis V, Benson S, Rosenberger C, Reidick D, Schedlowski M, Bingel U, Theysohn N, Forsting M, Gizewski ER. Neural mechanisms mediating the effects of expectation in visceral placebo analgesia: an fMRI study in healthy placebo responders and nonresponders. Pain. 2012;153(2): 382-90.

60. Geuter S, Buchel C. Facilitation of pain in the human spinal cord by nocebo treatment. J Neurosci. 2013;33(34):13784-90.

61. Petrovic $P$, Kalso E, Petersson KM, Andersson J, Fransson P, Ingvar M. A prefrontal non-opioid mechanism in placebo analgesia. Pain. 2010;150(1): 59-65.

62. Petrovic P, Kalso E, Petersson KM, Ingvar M. Placebo and opioid analgesiaimaging a shared neuronal network. Science. 2002;295(5560):1737-40.

63. Amanzio M, Benedetti F, Porro CA, Palermo S, Cauda F. Activation likelihood estimation meta-analysis of brain correlates of placebo analgesia in human experimental pain. Hum Brain Mapp. 2013;34(3):738-52.

64. Sawamoto N, Honda M, Okada T, Hanakawa T, Kanda M, Fukuyama H, Konishi J, Shibasaki $\mathrm{H}$. Expectation of pain enhances responses to nonpainful Somatosensory stimulation in the anterior Cingulate cortex and parietal operculum/posterior Insula: an event-related functional magnetic resonance imaging study. J Neurosci. 2000;20(19):7438-45.

65. Koyama T, McHaffie JG, Laurienti PJ, Coghill RC. The subjective experience of pain: where expectations become reality. Proc Natl Acad Sci U S A. 2005; 102(36):12950-5.

66. Keltner JR, Furst A, Fan C, Redfern R, Inglis B, Fields HL. Isolating the modulatory effect of expectation on pain transmission: a functional magnetic resonance imaging study. J Neurosci. 2006;26(16):4437-43.

67. Kong J, Gollub RL, Polich G, Kirsch I, Laviolette P, Vangel M, Rosen B, Kaptchuk TJ. A functional magnetic resonance imaging study on the neural mechanisms of hyperalgesic nocebo effect. J Neurosci. 2008; 28(49):13354-62.

68. Wager TD, Matre D, Casey KL. Placebo effects in laser-evoked pain potentials. Brain Behav Immun. 2006;20(3):219-30.

69. Piedimonte A, Guerra G, Vighetti S, Carlino E. Measuring expectation of pain: contingent negative variation in placebo and nocebo effects. Eur J Pain. 2017;21(5):874-85.

70. Carlino E, Torta DM, Piedimonte A, Frisaldi E, Vighetti S, Benedetti F. Role of explicit verbal information in conditioned analgesia. Eur J Pain. 2015;19(4):546-53.

71. Colloca L, Tinazzi M, Recchia S, Le Pera D, Fiaschi A, Benedetti F, Valeriani M. Learning potentiates neurophysiological and behavioral placebo analgesic responses. Pain. 2008;139(2):306-14.
72. Benedetti F, Pollo A, Lopiano L, Lanotte M, Vighetti S, Rainero I. Conscious expectation and unconscious conditioning in analgesic, motor, and hormonal placebo/nocebo responses. J Neurosci. 2003;23(10):4315-23.

73. Levine JD, Gordon NC, Fields HL. The mechanism of placebo analgesia. Lancet. 1978;2(8091):654-7.

74. Amanzio M, Benedetti F. Neuropharmacological dissection of placebo analgesia: expectation-activated opioid systems versus conditioningactivated specific subsystems. J Neurosci. 1999;19(1):484-94.

75. Benedetti F, Amanzio M, Maggi G. Potentiation of placebo analgesia by proglumide. Lancet. 1995;346(8984):1231.

76. Benedetti $F$. The opposite effects of the opiate antagonist naloxone and the cholecystokinin antagonist proglumide on placebo analgesia. Pain. 1996; 64(3):535-43.

77. Benedetti F, Amanzio M, Thoen W. Disruption of opioid-induced placebo responses by activation of cholecystokinin type-2 receptors. Psychopharmacology. 2011;213(4):791-7.

78. Benedetti F, Amanzio M, Rosato R, Blanchard C. Nonopioid placebo analgesia is mediated by CB1 cannabinoid receptors. Nat Med. 2011; 17(10):1228-30.

79. Zubieta JK, Bueller JA, Jackson LR, Scott DJ, Xu Y, Koeppe RA, Nichols TE, Stohler CS. Placebo effects mediated by endogenous opioid activity on muopioid receptors. J Neurosci. 2005;25(34):7754-62.

80. Wager TD, Scott DJ, Zubieta JK. Placebo effects on human mu-opioid activity during pain. Proc Natl Acad Sci U S A. 2007;104(26):11056-61.

81. Scott DJ, Stohler CS, Egnatuk CM, Wang H, Koeppe RA, Zubieta JK. Individual differences in reward responding explain placebo-induced expectations and effects. Neuron. 2007;55(2):325-36.

82. Scott DJ, Stohler CS, Egnatuk CM, Wang H, Koeppe RA, Zubieta JK. Placebo and nocebo effects are defined by opposite opioid and dopaminergic responses. Arch Gen Psychiatry. 2008;65(2):220-31.

83. Kessner S, Sprenger C, Wrobel N, Wiech K, Bingel U. Effect of oxytocin on placebo analgesia: a randomized study. JAMA. 2013;310(16):1733-5.

84. Colloca L, Pine DS, Ernst M, Miller FG, Grillon C. Vasopressin boosts placebo analgesic effects in women: a randomized trial. Biol Psychiatry. 2016;79(10):794-802.

85. Benedetti F, Durando J, Vighetti S. Nocebo and placebo modulation of hypobaric hypoxia headache involves the cyclooxygenase-prostaglandins pathway. Pain. 2014;155(5):921-8.

86. Bishop MD, Bialosky JE, Cleland JA. Patient expectations of benefit from common interventions for low back pain and effects on outcome: secondary analysis of a clinical trial of manual therapy interventions. J. Man Manip Ther. 2011;19(1):20-5.

87. Ferreira PH, Ferreira ML, Maher CG, Refshauge KM, Latimer J, Adams RD. The therapeutic alliance between clinicians and patients predicts outcome in chronic low back pain. Phys Ther. 2013;93(4):470-8.

88. Fuentes J, Armijo-Olivo S, Funabashi M, Miciak M, Dick B, Warren S, Rashiq S, Magee DJ, Gross DP. Enhanced therapeutic alliance modulates pain intensity and muscle pain sensitivity in patients with chronic low back pain: an experimental controlled study. Phys Ther. 2014;94(4):477-89.

89. Wand BM, Tulloch VM, George PJ, Smith AJ, Goucke R, O'Connell NE, Moseley GL. Seeing it helps: movement-related back pain is reduced by visualization of the back during movement. Clin J Pain. 2012;28(7):602-8.

90. Myers SS, Phillips RS, Davis RB, Cherkin DC, Legedza A, Kaptchuk TJ, Hrbek A, Buring JE, Post D, Connelly MT, et al. Patient expectations as predictors of outcome in patients with acute low back pain. J Gen Intern Med. 2008; 23(2):148-53.

91. Linde K, Witt CM, Streng A, Weidenhammer W, Wagenpfeil S, Brinkhaus B, Willich SN, Melchart D. The impact of patient expectations on outcomes in four randomized controlled trials of acupuncture in patients with chronic pain. Pain. 2007;128(3):264-71.

92. Kalauokalani D, Cherkin DC, Sherman KJ, Koepsell TD, Deyo RA. Lessons from a trial of acupuncture and massage for low back pain: patient expectations and treatment effects. Spine (Phila Pa 1976). 2001;26(13): $1418-24$.

93. Sherman KJ, Cherkin DC, Ichikawa L, Avins AL, Delaney K, Barlow WE, Khalsa PS, Deyo RA. Treatment expectations and preferences as predictors of outcome of acupuncture for chronic back pain. Spine (Phila Pa 1976). 2010; 35(15):1471-7.

94. George SZ, Robinson ME. Preference, expectation, and satisfaction in a clinical trial of behavioral interventions for acute and sub-acute low back pain. J Pain. 2010;11(11):1074-82. 
95. Skatteboe S, Roe C, Fagerland MW, Granan LP. Expectations of pain and functioning in patients with musculoskeletal disorders: a cross-sectional study. BMC Musculoskelet Disord. 2017;18(1):48.

96. Kongsted A, Vach W, Axo M, Bech RN, Hestbaek L. Expectation of recovery from low back pain: a longitudinal cohort study investigating patient characteristics related to expectations and the association between expectations and 3-month outcome. Spine (Phila Pa 1976). 2014;39(1):81-90.

97. Goossens ME, Vlaeyen JW, Hidding A, Kole-Snijders A, Evers SM. Treatment expectancy affects the outcome of cognitive-behavioral interventions in chronic pain. Clin J Pain. 2005;21:18-26.

98. Wasan AD, Kong J, Pham LD, Kaptchuk TJ, Edwards R, Gollub RL. The impact of placebo, psychopathology, and expectations on the response to acupuncture needling in patients with chronic low back pain. J Pain. 2010;11(6):555-63.

99. Witt CM, Schützler L, Lüdtke R, Wegscheider K, Willich SN. Patient characteristics and variation in treatment outcomes: which patients benefit most from acupuncture for chronic pain? Clin J Pain. 2011;27(6):550-5.

100. Vase L, Vollert J, Finnerup NB, Miao X, Atkinson G, Marshall S, Nemeth R, Lange $B$, Liss $C$, Price DD, et al. Predictors of the placebo analgesia response in randomized controlled trials of chronic pain: a meta-analysis of the individual data from nine industrially sponsored trials. Pain. 2015;156(9):1795-802

101. Graz B, Wietlisbach V, Porchet F, Vader JP. Prognosis or "curabo effect?": physician prediction and patient outcome of surgery for low back pain and sciatica. Spine (Phila Pa 1976). 2005;30(12):1448-52.

102. Darlow B, Fullen BM, Dean S, Hurley DA, Baxter GD, Dowell A. The association between health care professional attitudes and beliefs and the attitudes and beliefs, clinical management, and outcomes of patients with low back pain: a systematic review. Eur J Pain. 2012;16(1):3-17.

103. Sit RW, Yip BH, Chan DC, Wong SY. Primary care physicians' attitudes and beliefs towards chronic low back pain: an Asian study. PLoS One. 2015;10(1):e0117521.

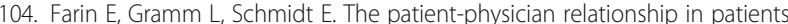
with chronic low back pain as a predictor of outcomes after rehabilitation. J Behav Med. 2013:36(3):246-58.

105. Zangrando F, Piccinini G, Tagliolini C, Marsilli G, losa M, Vulpiani MC, Paolucci T. The efficacy of a preparatory phase of a touch-based approach in treating chronic low back pain: a randomized controlled trial. J Pain Res. 2017:10:941-9.

106. Gardner T, Refshauge K, McAuley J, Goodall S, Hubscher M, Smith L. Patientled goal setting: a pilot study investigating a promising approach for the Management of Chronic low Back Pain. Spine (Phila Pa 1976). 2016;41(18): 1405-13.

107. Gardner T, Refshauge K, Smith L, McAuley J, Hubscher M, Goodall S. Physiotherapists' beliefs and attitudes influence clinical practice in chronic low back pain: a systematic review of quantitative and qualitative studies. J Phys. 2017;63(3):132-43.

108. Louw A, Zimne K, Landers MR, Luttrell M, Clair B, Mills J. A randomised controlled trial of 'clockwise' ultrasound for low back pain. South African J Physiotherapy. 2016;72(1):1-7.

109. Bishop MD, Mintken PE, Bialosky JE, Cleland JA. Patient expectations of benefit from interventions for neck pain and resulting influence on outcomes. J Orthop Sports Phys Ther. 2013;43(7):457-65.

110. Diers M, Zieglgansberger W, Trojan J, Drevensek AM, Erhardt-Raum G, Flor H. Site-specific visual feedback reduces pain perception. Pain. 2013;154(6):890-6.

111. Groeneweg R, Haanstra T, Bolman CAW, Oostendorp RAB, van Tulder MW Ostelo R. Treatment success in neck pain: the added predictive value of psychosocial variables in addition to clinical variables. Scand J Pain. 2017; 14:44-52.

112. Chester R, Jerosch-Herold C, Lewis J, Shepstone L. Psychological factors are associated with the outcome of physiotherapy for people with shoulder pain: a multicentre longitudinal cohort study. Br J Sports Med. 2016.[Epub ahead of print]

113. Louw A, Puentedura EJ, Reese D, Parker P, Miller T, Mintken PE. Immediate effects of mirror therapy in patients with shoulder pain and decreased range of motion. Arch Phys Med Rehabil. 2017;98(10):1941-7.

114. Abhishek A, Doherty M. Mechanisms of the placebo response in pain in osteoarthritis. Osteoarthr Cartil. 2013;21(9):1229-35.

115. Doherty M, Dieppe P. The "placebo" response in osteoarthritis and its implications for clinical practice. Osteoarthr Cartil. 2009;17(10):1255-62.

116. Zou K, Wong J, Abdullah N, Chen X, Smith T, Doherty M, Zhang W. Examination of overall treatment effect and the proportion attributable to contextual effect in osteoarthritis: meta-analysis of randomised controlled trials. Ann Rheum Dis. 2016:75(11):1964-70.

117. Coste J, Montel S. Placebo-related effects: a meta-narrative review of conceptualization, mechanisms and their relevance in rheumatology. Rheumatology (Oxford). 2017;56(3):334-43.

118. Zhang W, Robertson J, Jones AC, Dieppe PA, Doherty M. The placebo effect and its determinants in osteoarthritis: meta-analysis of randomised controlled trials. Ann Rheum Dis. 2008;67(12):1716-23.

119. Bannuru RR, McAlindon TE, Sullivan MC, Wong JB, Kent DM, Schmid CH. Effectiveness and implications of alternative placebo treatments: a systematic review and network meta-analysis of osteoarthritis trials. Ann Intern Med. 2015;163(5):365-72

120. White $P$, Bishop FL, Prescott $P$, Scott $C$, Little $P$, Lewith G. Practice, practitioner, or placebo? A multifactorial, mixed-methods randomized controlled trial of acupuncture. Pain. 2012:153(2):455-62.

121. Suarez-Almazor ME, Looney C, Liu Y, Cox V, Pietz K, Marcus DM, Street RL Jr. A randomized controlled trial of acupuncture for osteoarthritis of the knee: effects of patient-provider communication. Arthritis Care Res. 2010:62(9):1229-36

122. Street RL Jr, Cox V, Kallen MA, Suarez-Almazor ME. Exploring communication pathways to better health: clinician communication of expectations for acupuncture effectiveness. Patient Educ Couns. 2012; 89(2):245-51.

123. Lu DF, Hart LK, Lutgendorf SK, Perkhounkova Y. The effect of healing touch on the pain and mobility of persons with osteoarthritis: a feasibility study. Geriatr Nurs. 2013;34(4):314-22.

124. Forward JB, Greuter NE, Crisall SJ, Lester HF. Effect of structured touch and guided imagery for pain and anxiety in elective joint replacement patientsa randomized controlled trial: M-TIJRP. Pers J. 2015;19(4):18-28.

125. Shankland B, Beaton D, Ahmed S, Nedelec B. Effects of client-centered multimodal treatment on impairment, function, and satisfaction of people with thumb carpometacarpal osteoarthritis. J Hand Ther. 2017;

126. Nestoriuc Y, Orav EJ, Liang MH, Horne R, Barsky AJ. Prediction of nonspecific side effects in rheumatoid arthritis patients by beliefs about medicines. Arthritis Care Res. 2010;62(6):791-9.

127. Fors EA, Landmark T, Bakke $\varnothing$. Contextual and time dependent pain in fibromyalgia: an explorative study. BMC Res Notes. 2012;20(5):644.

128. Chen X, Zou K, Abdullah N, Whiteside N, Sarmanova A, Doherty M, Zhang $W$. The placebo effect and its determinants in fibromyalgia: meta-analysis of randomised controlled trials. Clin Rheumatol. 2017; 36(7):1623-30.

129. Hauser W, Bartram-Wunn E, Bartram C, Reinecke H, Tolle T. Systematic review: placebo response in drug trials of fibromyalgia syndrome and painful peripheral diabetic neuropathy-magnitude and patient-related predictors. Pain. 2011;152(8):1709-17.

130. Mitsikostas DD, Chalarakis NG, Mantonakis LI, Delicha EM, Sfikakis PP. Nocebo in fibromyalgia: meta-analysis of placebo-controlled clinical trials and implications for practice. Eur J Neurol. 2012;19(5):672-80.

131. Denison B. Touch the pain away: new research on therapeutic touch and persons with fibromyalgia syndrome. Holist Nurs Pract. 2004;18(3):142-51.

132. Kosek E, Rosen A, Carville S, Choy E, Gracely RH, Marcus H, Petzke F, Ingvar $M$, Jensen KB. Lower placebo responses after long-term exposure to fibromyalgia pain. J Pain. 2017;18(7):835-43.

133. Berthelot JM. The placebo effect in rheumatology: new data. Joint Bone Spine. 2011;78(2):161-5.

134. Häuser W, Bartram C, Bartram-Wunn E, Tölle T. Adverse events attributable to nocebo in randomized controlled drug trials in fibromyalgia syndrome and painful diabetic peripheral neuropathy: systematic review. Clin J Pain. 2012;28(5):437-51

135. Koog YH, Lee JS, Wi H. Nonspecific adverse events in knee osteoarthritis clinical trials: a systematic review. PLoS One. 2014;9(11):e111776.

136. Reiter-Niesert S, Boers M, Detert J. Short-term placebo response in trials of patients with symptomatic osteoarthritis: differences between hip and knee Osteoarthr Cartil. 2016;24(6):1007-11.

137. Zhang W, Doherty M. Efficacy paradox and proportional contextual effect (PCE). Clin Immunol. 2017;17:30539.

138. Puhl AA, Reinhart CJ, Rok ER, Injeyan HS. An examination of the observed placebo effect associated with the treatment of low back pain - a systematic review. Pain Res Manag. 2011;16(1):45-52.

139. Menke JM. Do manual therapies help low back pain? A comparative effectiveness meta-analysis. Spine (Phila Pa 1976). 2014;39(7):E463-72. 
140. Auer CJ, Glombiewski JA, Doering BK, Winkler A, Laferton JA, Broadbent E, Rief W. Patients' expectations predict surgery outcomes: a meta-analysis. Int J Behav Med. 2016;23(1):49-62.

141. Muller M, Kamping S, Benrath J, Skowronek H, Schmitz J, Klinger R, Flor H. Treatment history and placebo responses to experimental and clinical pain in chronic pain patients. Eur J Pain. 2016;20(9):1530-41.

142. Birkhauer J, Gaab J, Kossowsky J, Hasler S, Krummenacher P, Werner C, Gerger $\mathrm{H}$. Trust in the health care professional and health outcome: a metaanalysis. PLoS One. 2017;12(2):e0170988.

143. Linton SJ, Vlaeyen J, Ostelo R. The back pain beliefs of health care providers: are we fear-avoidant? J Occup Rehabil. 2002;12(4):223-32.

144. Witt CM, Martins F, Willich SN, Schutzler L. Can I help you? Physicians' expectations as predictor for treatment outcome. Eur J Pain. 2012; 16(10):1455-66.

145. Mistiaen P, van Osch M, van Vliet L, Howick J, Bishop FL, Di Blasi Z, Bensing $J$, van Dulmen $S$. The effect of patient-practitioner communication on pain: a systematic review. Eur J Pain. 2016;20(5):675-88.

146. Peerdeman KJ, van Laarhoven Al, Keij SM, Vase L, Rovers MM, Peters ML, Evers AW. Relieving patients' pain with expectation interventions: a metaanalysis. Pain. 2016;157(6):1179-91.

147. Decker S, Wardell DW, Cron SG. Using a healing touch intervention in older adults with persistent pain: a feasibility study. J Holist Nurs. 2012;30(3):205-13.

148. Wardell DW, Decker SA, Engebretson JC. Healing touch for older adults with persistent pain. Holist Nurs Pract. 2012;26(4):194-202.

149. Dibbelt S, Schaidhammer M, Fleischer C, Greitemann B. Patient-doctor interaction in rehabilitation: the relationship between perceived interaction quality and long-term treatment results. Patient Educ Couns. 2009;76(3):328-35

150. Kelley JM, Kraft-Todd G, Schapira L, Kossowsky J, Riess H. The influence of the patient-clinician relationship on healthcare outcomes: a systematic review and meta-analysis of randomized controlled trials. PLoS One. 2014;9(4):e94207.

151. Yakunchikov DY, Olechowski CJ, Simmonds MK, Verrier MJ, Rashiq S, McWilliams LA, Sobolev IA, Dick BD. The effect of social observational learning, empathy and Catastrophizing in chronic pain patients during acute pain induction. Pain Med. 2017;18(5):871-8.

152. Goubert L, Vlaeyen JW, Crombez G, Craig KD. Learning about pain from others: an observational learning account. J. Pain. 2011;12(2):167-74

153. Jonas WB, Crawford C, Colloca L, Kaptchuk TJ, Moseley B, Miller FG, Kriston L, Linde $\mathrm{K}$, Meissner $\mathrm{K}$. To what extent are surgery and invasive procedures effective beyond a placebo response? A systematic review with meta-analysis of randomised, sham controlled trials. BMJ Open. 2015;5(12):e009655

154. Gu AP, Gu CN, Ahmed AT, Murad MH, Wang Z, Kallmes DF, Brinjikji W. Sham surgical procedures for pain intervention result in significant improvements in pain: systematic review and meta-analysis. J Clin Epidemiol. 2017;83:18-23.

155. Laursen J, Danielsen A, Rosenberg J. Effects of environmental design on patient outcome: a systematic review. Health Environ Res Des J. 2014;7(4): 108-19.

156. Iyendo TO, Uwajeh PC, Ikenna ES. The therapeutic impacts of environmental design interventions on wellness in clinical settings: a narrative review. Complement Ther Clin Pract. 2016;24:174-88.

157. Iyendo TO. Exploring the effect of sound and music on health in hospital settings: a narrative review. Int J Nurs Stud. 2016;63:82-100.

158. Nijs J, Roussel N, Paul van Wilgen C, Koke A, Smeets R. Thinking beyond muscles and joints: therapists' and patients' attitudes and beliefs regarding chronic musculoskeletal pain are key to applying effective treatment. Man Ther. 2013;18(2):96-102.

159. Edwards I, Richardson B. Clinical reasoning and population health: decision making for an emerging paradigm of health care. Physiother Theory Pract. 2008;24(3):183-93.

160. De Felice M, Ossipov MH. Cortical and subcortical modulation of pain. Pain Manag. 2016;6(2):111-20.

161. Vase $L, J L r R$, Price DD. A comparison of placebo effects in clinical analgesic trials versus studies of placebo analgesia. Pain. 2002;99(3):443-52.

162. Vase L, Petersen GL, Riley JL 3rd, Price DD. Factors contributing to large analgesic effects in placebo mechanism studies conducted between 2002 and 2007. Pain. 2009;145(1-2):36-44.

163. Price DD, Riley JL 3rd, Vase L. Reliable differences in placebo effects between clinical analgesic trials and studies of placebo analgesia mechanisms. Pain. 2003;104:715-6.
164. Petersen GL, Finnerup NB, Colloca L, Amanzio M, Price DD, Jensen TS, Vase L. The magnitude of nocebo effects in pain: a meta-analysis. Pain. 2014; 155(8):1426-34

165. Hróbjartsson A, Gøtzsche PC. Is the placebo powerless? An analysis of clinical trials comparing placebo with no treatment. N Engl J Med. 2001; 344(21):1594-602

166. Hróbjartsson A, Gøtzsche PC. Is the placebo powerless? Update of a systematic review with 52 new randomized trials comparing placebo with no treatment. J Intern Med. 2004:256(2):91-100.

167. Hróbjartsson A, Gøtzsche PC. Placebo interventions for all clinical conditions. Cochrane Database Syst Rev. 2010;20(1):CD003974

168. Klinger R, Flor $\mathrm{H}$. Clinical and ethical implications of placebo effects: enhancing patients' benefits from pain treatment. Handb Exp Pharmacol. 2014;225:217-35.

169. Bishop FL, Coghlan B, Geraghty AW, Everitt H, Little P, Holmes MM, Seretis $D$, Lewith $G$. What techniques might be used to harness placebo effects in non-malignant pain? A literature review and survey to develop a taxonomy. BMJ Open. 2017;7(6):e015516.

170. Colloca L, Grillon C. Understanding placebo and nocebo responses for pain management. Curr Pain Headache Rep. 2014;18(6):419.

171. Carlino E, Pollo A, Benedetti F. The placebo in practice: how to use it in clinical routine. Curr Opin Support Palliat Care. 2012;6(2):220-5.

172. Klinger R, Colloca L, Bingel U, Flor H. Placebo analgesia: clinical applications. Pain. 2014;155(6):1055-8

173. Klinger R, Blasini M, Schmitz J, Colloca L. Nocebo effects in clinical studies: hints for pain therapy. Pain Rep. 2017;2(2):e586.

174. Rief W, Shedden-Mora MC, Laferton JA, Auer C, Petrie KJ, Salzmann S, Schedlowski M, Moosdorf R. Preoperative optimization of patient expectations improves long-term outcome in heart surgery patients: results of the randomized controlled PSY-HEART trial. BMC Med. 2017;15(1):4.

175. Younger J, Gandhi V, Hubbard E, Mackey S. Development of the Stanford expectations of treatment scale (SETS): a tool for measuring patient outcome expectancy in clinical trials. Clin Trials. 2012;9(6):767-76.

176. Bingel U. Avoiding nocebo effects to optimize treatment outcome. JAMA 2014;312(7):693-4.

177. Amanzio M, Palermo S, Skyt I, Vase L. Lessons learned from Nocebo effects in clinical trials for pain conditions and neurodegenerative disorders. J Clin Psychopharmacol. 2016;36(5):475-82.

178. Wertli MM, Held U, Lis A, Campello M, Weiser S. Both positive and negative beliefs are important in patients with spine pain: findings from the Occupational and Industrial Orthopaedic Center registry. Spine J. 2017. [Epub ahead of print]

179. Schenk L, Krimmel SR, Colloca L. Observe to get pain relief: current evidence and potential mechanisms of socially learned pain modulation. Pain. 2017:158(11):2077-81.

180. Koban L, Jepma M, Geuter S, Wager TD. What's in a word? How instructions, suggestions, and social information change pain and emotion. Neurosci Biobehav Rev. 2017:81(Pt A):29-42.

181. Benedetti F, Amanzio M. The placebo response: how words and rituals change the patient's brain. Patient Educ Couns. 2011;84(3):413-9.

182. Benedetti F. Placebo-induced improvements: how therapeutic rituals affect the patient's brain. J Acupunct Meridian Stud. 2012;5(3):97-103.

183. Webster RK, Weinman J, Rubin GJ. A systematic review of factors that contribute to nocebo effects. Health Psychol. 2016;35(12):1334-55.

184. Booth J, Moseley GL, Schiltenwolf M, Cashin A, Davies M, Hubscher M. Exercise for chronic musculoskeletal pain: a biopsychosocial approach. Musculoskeletal care. 2017;15(4):413-21.

185. Wijma AJ, Bletterman AN, Clark JR, Vervoort S, Beetsma A, Keizer D, Nijs J, Van Wilgen CP. Patient-centeredness in physiotherapy: what does it entail? A systematic review of qualitative studies. Physiother Theory Pract. 2017; 33(11):825-40

186. Stevens A, Koke A, van der Weijden T, Beurskens A. The development of a patient-specific method for physiotherapy goal setting: a user-centered design. Disabil Rehabil. 2017; 13:1-8. [Epub ahead of print]

187. Liu T. Route of placebo administration: robust placebo effects in laboratory and clinical settings. Neurosci Biobehav Rev. 2017:83:451-7.

188. Howick J, Rees S. Overthrowing barriers to empathy in healthcare: empathy in the age of the internet. J R Soc Med. 2017;110(9):352-7.

189. Henry SG, Bell RA, Fenton JJ, Kravitz RL. Communication about chronic pain and opioids in primary care: Impact on patient and physician visit experience. Pain. 2017. [Epub ahead of print] 
190. Babatunde F, MacDermid J, Maclntyre N. Characteristics of therapeutic alliance in musculoskeletal physiotherapy and occupational therapy practice: a scoping review of the literature. BMC Health Serv Res. 2017;17(1):375.

191. Colloca L, Finniss D. Nocebo effects, patient-clinician communication, and therapeutic outcomes. JAMA. 2012;307(6):567-8.

192. Howick J, Lewith G, Mebius A, Fanshawe TR, Bishop F, van Osch M, van Dulmen S, Christelis N, Kaptchuk T, Mistiaen P. Positive messages may reduce patient pain: a meta-analysis. Eur J Intern Med. 2017;11:31-8.

193. Fassler M, Meissner K, Schneider A, Linde K. Frequency and circumstances of placebo use in clinical practice-a systematic review of empirical studies. BMC Med. 2010;8:15.

194. Baldwin MJ, Wartolowska K, Carr AJ. A survey on beliefs and attitudes of trainee surgeons towards placebo. BMC Surg. 2016;16(1):27.

195. Wartolowska K, Beard DJ, Carr AJ. Attitudes and beliefs about placebo surgery among orthopedic shoulder surgeons in the United Kingdom. PLoS One. 2014;9(3):e91699.

196. Berthelot JM, Maugars Y, Abgrall M, Prost A. Interindividual variations in beliefs about the placebo effect: a study in 300 rheumatology inpatients and 100 nurses. Joint Bone Spine. 2001;68(1):65-70.

197. Kisaalita N, Staud R, Hurley R, Robinson M. Placebo use in pain management: the role of medical context, treatment efficacy, and deception in determining placebo acceptability. Pain. 2014;155(12):2638-45.

198. Hughes J, Greville-Harris M, Graham CA, Lewith G, White P, Bishop FL. What trial participants need to be told about placebo effects to give informed consent: a survey to establish existing knowledge among patients with back pain. J Med Ethics. 2017:43(12):867-70

199. Miller FG, Colloca L. The placebo phenomenon and medical ethics: rethinking the relationship between informed consent and risk-benefit assessment. Theor Med Bioeth. 2011;32(4):229-43.

200. Miller FG, Colloca L. The legitimacy of placebo treatments in clinical practice: evidence and ethics. Am J Bioeth. 2009;9(12):39-47.

201. Blease C, Colloca L, Kaptchuk TJ. Are open-label placebos ethical? Informed consent and ethical equivocations. Bioethics. 2016;30(6):407-14.

202. Alfano M. Placebo effects and informed consent. Am J Bioeth. 2015, 15(10):3-12

203. Charlesworth JEG, Petkovic G, Kelley JM, Hunter M, Onakpoya I, Roberts N, Miller FG, Howick J. Effects of placebos without deception compared with no treatment: a systematic review and meta-analysis. J Evid Based Med. 2017;10(2):97-107

204. Annoni M, Miller FG. Placebo effects and the ethics of therapeutic communication: a pragmatic perspective. Kennedy Inst Ethics J. 2016;26(1): 79-103.

205. Carvalho C, Caetano JM, Cunha L, Rebouta P, Kaptchuk TJ, Kirsch I. Openlabel placebo treatment in chronic low back pain: a randomized controlled trial. Pain. 2016;157(12):2766-72

206. Bialosky JE, Robinson ME. Placebo disclosure does not result in negative changes in mood or attitudes towards health care or the provider. J Man Manip Ther. 2017;25(3):151-9.

207. Benedetti F, Carlino E, Piedimonte A. Increasing uncertainty in CNS clinical trials: the role of placebo, nocebo, and Hawthorne effects. Lancet Neurol. 2016;15(7):736-47.

208. Colloca L, Miller FG. Harnessing the placebo effect: the need for translational research. Philos Trans R Soc Lond Ser B Biol Sci. 2011;366(1572): 1922-30.

209. Linde K, Fassler M, Meissner K. Placebo interventions, placebo effects and clinical practice. Philos Trans R Soc Lond Ser B Biol Sci. 2011; 366(1572):1905-12.

210. Rossettini G, Testa M. Manual therapy RCTs: should we control placebo in placebo control? Eur. J Phys Rehabil Med. 2017. [Epub ahead of print]

211. Puhl AA, Reinhart CJ, Doan JB, Vernon $H$. The quality of placebos used in randomized, controlled trials of lumbar and pelvic joint thrust manipulationa systematic review. Spine J. 2017;17(3):445-56

212. Cerritelli F, Verzella M, Cicchitti L, D'Alessandro G, Vanacore N. The paradox of sham therapy and placebo effect in osteopathy: a systematic review. Medicine. 2016;95(35):e4728.

213. Maddocks M, Kerry R, Turner A, Howick J. Problematic placebos in physical therapy trials. J Eval Clin Pract. 2016;22(4):598-602.

214. Frisaldi E, Shaibani A, Benedetti F. Why we should assess Patients' expectations in clinical trials. Pain Ther. 2017;6(1):107-10.

215. Peerdeman KJ, van Laarhoven Al, Peters ML, Evers AW. An integrative review of the influence of expectancies on pain. Front Psychol. 2016;7:1270.
216. Laferton JA, Kube T, Salzmann S, Auer CJ, Shedden-Mora MC. Patients' expectations regarding medical treatment: a critical review of concepts and their assessment. Front Psychol. 2017;8:233.

217. Greco CM, Yu L, Johnston KL, Dodds NE, Morone NE, Glick RM, Schneider MJ, Klem ML, McFarland CE, Lawrence S, et al. Measuring nonspecific factors in treatment: item banks that assess the healthcare experience and attitudes from the patient's perspective. Qual Life Res. 2016;25(7):1625-34.

218. Simmons K, Ortiz R, Kossowsky J, Krummenacher P, Grillon C, Pine D, Colloca L. Pain and placebo in pediatrics: a comprehensive review of laboratory and clinical findings. Pain. 2014;155(11):2229-35.

219. Savvas SM, Zelencich LM, Gibson SJ. Should placebo be used routinely for chronic pain in older people? Maturitas. 2014;79(4):389-400

220. Bingel U, Colloca L, Vase L. Mechanisms and clinical implications of the placebo effect: is there a potential for the elderly? A mini-review. Gerontology. 2011:57(4):354-63.

221. Nijs J, Apeldoorn A, Hallegraeff H, Clark J, Smeets R, Malfliet A, Girbes EL, De Kooning M, Ickmans K. Low back pain: guidelines for the clinical classification of predominant neuropathic, nociceptive, or central sensitization pain. Pain Physician. 2015;18(3):E333-46.

222. Osani MC, Bannuru RR. What clinicians should know about differential placebo effects. J Comp Eff Res. 2016;5(3):289-96.

\section{Submit your next manuscript to BioMed Central and we will help you at every step:}

- We accept pre-submission inquiries

- Our selector tool helps you to find the most relevant journal

- We provide round the clock customer support

- Convenient online submission

- Thorough peer review

- Inclusion in PubMed and all major indexing services

- Maximum visibility for your research

Submit your manuscript at www.biomedcentral.com/submit 